\title{
PENGARUH TINGKAT PENGETAHUAN KEWIRAUSAHAAN TERHADAP MINAT MENJADI ENTREPRENEUR PADA MAHASISWA \\ (Studi kasus mahasiswa UBSI cabang Salemba 22 Jakarta)
}

\author{
Fajar Diah Astut ${ }^{\mathrm{i}}$, Rawit Sartika ${ }^{2}$, Panji Suratriadi ${ }^{3}$ \\ 1,2,3 Universitas Bina Sarana Informatika Jakarta \\ suratriadi@gmail.com
}

\begin{abstract}
The Central Statistics Agency announced that the unemployment rate until August 2019 became 7.05 million people. Interference for young people with a college education background for diplomas from 2017-2019 rose 8.5\%, for university graduates or graduates from 2017-2019 it rose to $25 \%$. This situation should be a concern for students to create jobs by becoming an entrepreneur. The research method used is quantitative methods by conducting surveys and interviews and processing the data using SPSS 19. The results of data processing obtained correlation/relationship coefficient $(R)=0.949$, and the coefficient of determination $\left(\mathrm{R}^{2}\right)$ of $\mathrm{R}^{2}=0.901$, it can be said the level of entrepreneurial knowledge $90.1 \%$ strongly influence students' interest in becoming entrepreneurs, the remaining $9.9 \%$ is influenced by other factors. And the simple regression equation results are $\mathrm{Y}=0.517+0.486 \mathrm{X}$, meaning that each addition of 1 (one) business will increase the amount of student interest in becoming an entrepreneur by 0.486 . It can be said that the interest of students to become entrepreneurs is very strongly influenced by the level of entrepreneurial knowledge.
\end{abstract}

Keywords: Entrepreneurship Knowledge, Interest in Becoming Entrepreneurs, Student

\begin{abstract}
Abstrak: Badan Pusat Statistik mengumumkan bahwa angka pengangguran sampai dengan Agustus 2019 menjadi 7,05 juta orang. Pengganggruan untuk generasi muda dengan latar pendidikan perguruan tinggi untuk diploma dari tahun 2017-2019 naik 8,5\%, untuk lulusan universitas atau sarjana dari tahun 2017-2019 naik menjadi 25\%. Keadaan ini harus menjadi perhatiaan bagi mahasiswa untuk menciptakan lapangan pekerjaan dengan cara menjadi pengusaha (entrepreneur). Metode penelitian yang digunakan metode kuantitatif dengan melakukan survey dan wawancara, serta pengolahan datanya menggunakan SPSS 19. Hasil pengolahan data didapat nilai koefisien korelasi/ hubungan $(\mathrm{R})=0,949$, dan koefisien determiniasi $\left(\mathrm{R}^{2}\right)$ sebesar $\mathrm{R}^{2}=0,901$, dapat dikatakan tingkat pengetahuan kewirausahaan $90,1 \%$ sangat kuat mempengaruhi minat mahasiswa menjadi entrepreneur, sisanya $9,9 \%$ dipengaruhi oleh faktor lain. Dan hasil persamaan regresi sederhananya adalah $\mathrm{Y}=0,517+0,486 \mathrm{X}$, artinya setiap penambahan 1 (satu) usaha akan menambah besar minat mahasiswa menjadi etrepreneur sebesar 0,486. Dapat dikatakan bahwa minat mahasiswa untuk menjadi entrepreneur sangat kuat dipengaruhi oleh tingkat pengetahuan kewirausahaan.
\end{abstract}

Kata Kunci: Pengetahuan Kewirausahaan, Minat Menjadi Enterpreneur, Mahasiswa 


\section{PENDAHULUAN}

Menurut Badan Pusat Statistik sebagaimana dikutif dari media berita online cnn indonesia, bahwa angka pengangguran naik 50 ribu orang per Agustus 2019, dimana angka penggangguran per 2018 adalah 7 juta orang, sehingga angka pengangguran sampai dengan Agustus 2019 menjadi 7,05 juta orang. Media online katadata juga mempublikasikan data Badan Pusat Statistik bahwa pengganggruan terus meningkat untuk generasi muda dengan latar pendidikan perguruan tinggi, untuk diploma 1,2,3 dari tahun 2017-2019 naik 8,5\%, untuk lulusan universitas dari tahun 2017-2019 naik menjadi 25\%. Dari 129,4 juta penduduk Indonesia yang bekerja $41 \%$ berlatar belakang pendidikan SD ke bawah, 18\% dengan latar belakang SMP, juga 18\% SMA, dan SMK 11\%, untuk universitas 10\%, dan diploma $1 / 2 / 3$ sebanyak $3 \%$.

Paparan data yang tersaji diatas merupakan tantangan bagi pemerintah untuk melakukan berbagai upaya dalam menekan angka pengangguran ke tingkat yang serendah-rendahnya. Oleh karena itu pemeritah telah melakukan berbagai upaya diantaranya melakukan pembukaan lapangan kerja melalui program padat karya dengan pembangunan infrastruktur di seluruh Indonesia, dan juga memberikan kemudahan berusaha bagi investor asing. Sebagaimana diberitakan media online kompas.com bahwa pemerintah telah memberikan kemudahan bagi investasi asing dalam kemudahan berusaha, diharapkan dampak dari investasi asing akan dapat menyerap tenaga kerja seluas luasnya.

Akan tetapi pastilah tidak semua pengangguran dapat diserap dalam proyek infrastruktur tersebut mengingat kapasitas daya tampung dan juga kualifikasi pegawai yang dibutuhkkan dalam proyek teresebut belum tentu sesuai. Maka dari kenyataan tersebut kita tidak mungkin hanya mengandalkan pemerintah untuk memberikan lapangan kerja, akan tetapi kita harus membuka lapangan kerja dengan menjadi wirausaha (entrepreneur) agar dapat menjamin kehidupan kita sendiri dan mambantu orang lain bekerja pada usaha yang kita buat.

Mahasiswa sebagai generasi cerdas saat ini juga diharapkan mampu berpartisipasi ikut menjadi pengusaha (entrepreneur). Sehingga mahasiswa tidak lagi berorientasi menjadi pegawai akan tetapi menjadi pengusaha yang sukses dengan memiliki karyawan yang banyak di masa mendatang. Seiring dengan kemajuan informasi dan 
teknologi maka informasi tetang bagaimana menjadi wirausaha, ide-ide dalam bisnis serta cara-cara mengembangkan wirausaha sudah banyak di internet.

Mahasiswa Universitas Bina Sarana Informatika (UBSI) di cabang Salemba 22 selama ini telah mengikuti perkuliahaan kewirausahaan (enterpreneurship) yang di akhir sesi diberikan praktek workshop pameran enterpreneur dengan mempraktekan ide usaha yang dibimbing oleh para dosen yang kompeten dibidangnya. Namun apakah mahasiswa berminat menjadi entrepreneur setalah diberikan pengetahuan tentang kewirausahaan.

Pengetahuan merupakan hal terpenting dalam diri manusia untuk dapat memulai aktivitasnya dalam rangka mewujudkan apa yang diinginkannya. Dalam mencapai kesuksesan dibidang kewirausahaan pun mutlak harus dimiliki pengetahuan tetang kewirausahaan. Menurut Kuntowicaksono (2012), bahwa pengetahuan kewirausahaan adalah pemahaman seseorang terhadap wirausaha dengan berbagai karakter positif, inovatif dan kreatif dalam mengembangkan peluang-peluang usaha menjadi kesempatan usaha yang menguntungkan dirinya dan masyarakat atau konsumennya.

Dan menurut Suryana (2014) bahwa pengetahuan kewirausahaan yang harus dimiliki seseorang meliputi pengetahuan:

1. Pengetahuan mengenai usaha yang akan dirintis

2. Pengetahuan tentang peran dan tanggung jawab

3. Pengetahuan tentang kepribadian dan kemampuan diri

4. Pengetahuan tentang manajemen dan organisasi bisnis

Pengetahuan yang sudah dimiliki memungkinkan manusia akan cenderung melakukan aktivitas sesuai dengan latar belakang pengetahuan yang dimilikinya tersebut. Begitu juga seorang Entrepreneur, maka ia akan melakukan segala aktifitas yang dapat menghasilkan keuntungan yang berlipat ganda dari setiap usaha yang dilakukannya. Enterpreneur menurut Ebert, Griffin (2003) adalah pelaku bisnis yang menerima gabungan antara resiko dan peluang yang menyangkut dalam menciptakan dan mengoperasikan peluang usaha baru.

Menurut Zimmerer, Scarborough (2008) bahwa enterpreneur adalah seseorang yang menciptakan bisnis baru ditengah resiko dan ketidakpastian sebagai sebuah tujuan untuk mencapai keuntungan dan pertumbuhan dengan dengan 
mengidentifikasi peluang dan mengumpulkan sumber daya yang penting sebagai modal utama.

Entrepreneur merupakan salah satu pilihan profesi yang sangat menjanjikan masa depan, maka mahasiswa dapat memulainya untuk mendapatkan masa depan yang cerah. Menurut hartaji (2012) mahasiswa adalah seseorang yag sedang dalam proses menimba ilmu atau sedang belajar terdaftar di salah satu bentuk perguruan tinggi yang terdiri dari sekolah tinggi, politeknik, institut dan universitas. Menurut Yusuf (2012) bahwa perkembangan usia mahasiswa berada pada kisaran usia 18 tahun hingga 25 tahun, usia tersebut disebut sebagai pemantapan pendirian hidup. Menjadi Entrepreneur dapat diawali dari memiliki pengetahuan yang berkaitan dengan kewirausahaan, sehingga apabila telah memiliki banyak pengetahuan tentang kewirausaan maka akan timbul minat menjadi Entrepreneur.

Minat secara teori menurut Winkel (2004) yaitu persaaan tertarik dan senang yang dapat membuat orang untuk mulai dapat menikmati sesuatu yang dihadapi atau dikerjakannya. Dan menurut Slameto (2003), minat adalah suatu rasa lebih suka dan rasa ketertarikan pada suatu hal atau aktivitas tanpa ada yang menyuruh, yang merupakan penerimaan akan suatu hubungan antara diri sendiri dengan sesuatu di luar diri sendiri semakin kuat dan semakin dekat hubungan tersebut, maka semakin besar pula minatnya.

\section{METODE}

Peneliti menyusun konsep kerangka penelitian tentang pengaruh tingkat pengetahuan kewirausahaan terhadap minat menjadi entrepreneur pada mahasiswa

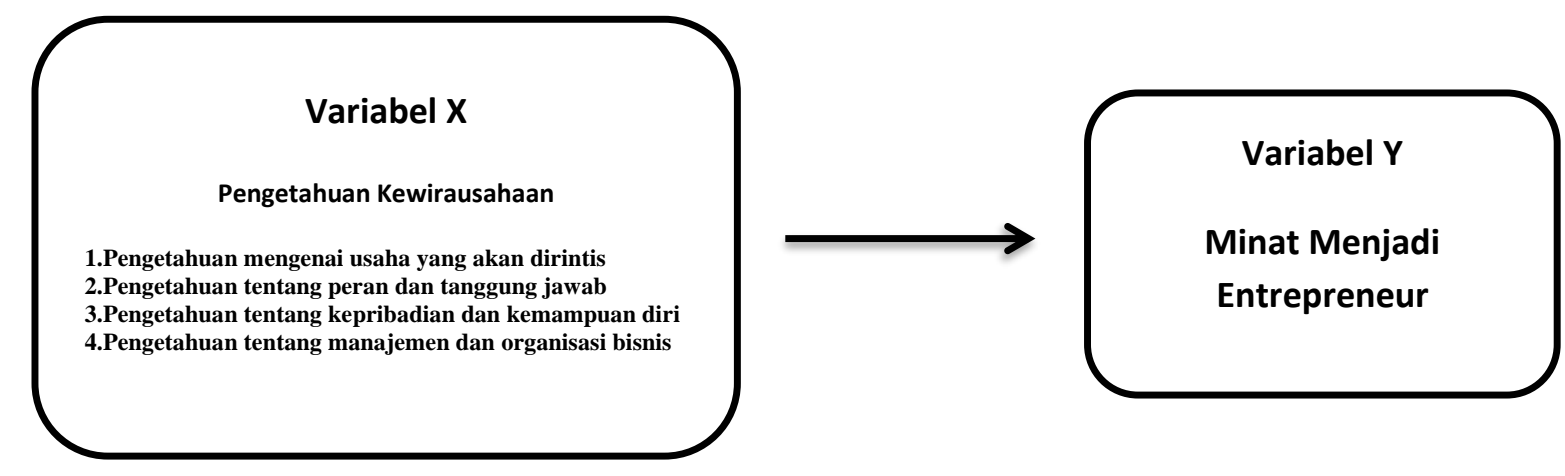




\section{Rumusan masalah/ Hipotesis}

$\mathrm{HO}=$ Tidak ada pengaruh tingkat pengetahuan kewirausahaan terhadap minat menjadi entrepreneur pada mahasiswa.

H1 = Ada pengaruh tingkat pengetahuan kewirausahaan terhadap minat menjadi entrepreneur pada mahasiswa.

\section{HASIL DAN PEMBAHASAN}

\section{Populasi dan Sampel}

Jumlah populasi mahasiswa Universitas Bina Sarana Informatika (UBSI) kampus cabang Salemba 22 adalah sebagai berikut:

\begin{tabular}{|l|c|}
\hline Populasi & Jumlah \\
\hline Laki laki & 580 \\
\hline Wanita & 632 \\
\hline Total & 1.212 \\
\hline
\end{tabular}

Sumber: kampus UBSI

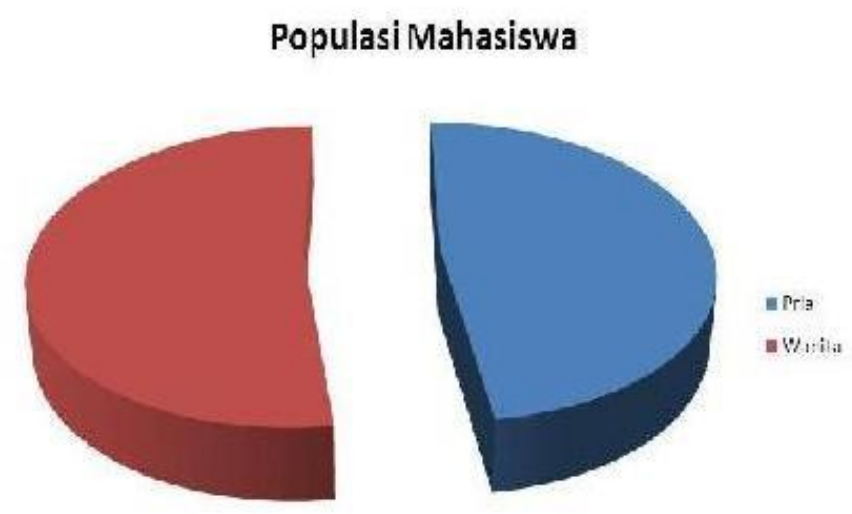

Bila kita persentasekan maka jumlah mahasiswa laki laki ssebanyak $47,85 \%$ dan sisanya mahasiswa wanita 52,15\%.

Dari populasi tersebut diambil sampel dengan menggunakan rumus Slovin sebagai berikut:

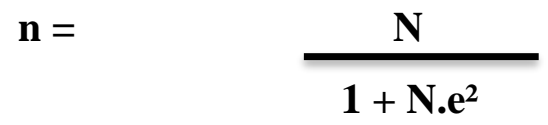

$\mathrm{n}=$ jumlah sampel

$\mathrm{N}=$ jumlah populasi 
$\mathrm{e}=$ batas toleransi kesalahan $(10 \%)$

$$
\begin{aligned}
\mathbf{n} & =\frac{1.212}{1+\left(\mathbf{1 . 2 1 2} \times\left(\mathbf{0 , 1 ^ { 2 } ) )}\right.\right.} \\
& =\quad 92,37 \text { pembulatan } 92 \text { mahasiswa }
\end{aligned}
$$

\section{Validitas}

Menurut Arikunto (2006) bahwa validitas adalah nilai yang menunjukkan kesahihan suatu data dalam instrumen penelitian. Nilai validitas data X (Tingkat pengetahuan kewirausahaan) dan validitas data Y (Minat menjadi entreprenuer) diolah dengan menggunakan program statistik SPSS 19. Dan data $r$ tabel dengan rumus $\mathrm{df}=\mathrm{N}-2$ dengan uji satu arah tingkat signifikansi 0,05 diketemukan angka pada $\mathrm{r}$ tabel sebesar 0,1726. Maka apabila $\mathrm{r}$ hitung lebih besar dari pada $\mathrm{r}$ tabel maka data tersebut kita katakan valid.

\section{Validitas Data $X$ (tingkat pengetahuan entrepreneur)}




\begin{tabular}{|c|c|c|c|c|c|c|c|c|c|c|}
\hline \multicolumn{11}{|c|}{ Correlations } \\
\hline & & PER1 & PER2 & PER3 & PER4 & PER5 & PER6 & PER7 & PER8 & T_SKOR \\
\hline \multirow[t]{3}{*}{ PER1 } & Pearson Correlation & 1 & $.254^{n}$ &,- 053 &,- 031 & $.500^{\mathrm{xx}}$ &,- 031 &,- 031 & $.275^{\mathrm{xx}}$ & $.421^{\pi x}$ \\
\hline & Sig. (2-tailed) & &, 014 & .614 & .766 &, 000 & .766 & .766 &, 008 &, 000 \\
\hline & $N$ & 92 & 92 & 92 & 92 & 92 & 92 & 92 & 92 & 92 \\
\hline \multirow[t]{3}{*}{ PER2 } & Pearson Correlation & $.254^{x}$ & 1 & $.232^{x}$ & $.215^{x}$ & $.239^{x}$ & $215^{x}$ & $.215^{x}$ & $.364^{x x}$ & $.558^{x x}$ \\
\hline & Sig. (2-tailed) &, 014 & & .026 & .040 &, 022 & .040 & .040 &, 000 &, 000 \\
\hline & $N$ & 92 & 92 & 92 & 92 & 92 & 92 & 92 & 92 & 92 \\
\hline \multirow[t]{3}{*}{ PER3 } & Pearson Correlation &,- 053 & $.232^{x}$ & 1 & $.976^{\mathrm{xx}}$ &,- 096 & $.976^{\pi x}$ & $.976^{x x}$ & .156 & $.786^{\mathrm{xx}}$ \\
\hline & Sig. (2-tailed) & .614 &, 026 & & .000 &, 363 &, 000 & .000 & .136 &, 000 \\
\hline & $N$ & 92 & 92 & 92 & 92 & 92 & 92 & 92 & 92 & 92 \\
\hline \multirow[t]{3}{*}{ PER4 } & Pearson Correlation &,- 031 & $.215^{x}$ & $976^{2 x}$ & 1 &,- 066 & $1,000^{\mathrm{xx}}$ & $1,000^{x x}$ & .180 & $.808^{\mathrm{nx}}$ \\
\hline & Sig. (2-tailed) & .766 &, 040 &, 000 & & .530 &, 000 & .000 &, 085 &, 000 \\
\hline & $N$ & 92 & 92 & 92 & 92 & 92 & 92 & 92 & 92 & 92 \\
\hline \multirow[t]{3}{*}{ PER5 } & Pearson Correlation & $.500^{\mathrm{xx}}$ & $.239^{x}$ &,- 096 &,- 066 & 1 &,- 066 &,- 066 & .200 & $.356^{\pi x}$ \\
\hline & Sig. (2-tailed) & .000 &, 022 & .363 & .530 & & .530 & .530 &, 056 &, 000 \\
\hline & $N$ & 92 & 92 & 92 & 92 & 92 & 92 & 92 & 92 & 92 \\
\hline \multirow[t]{3}{*}{ PER6 } & Pearson Correlation &,- 031 & $.215^{x}$ & $.976^{x x}$ & $1,000^{x x}$ &,- 066 & 1 & $1,000^{x x}$ & .180 & $.808^{x x}$ \\
\hline & Sig. (2-tailed) & .766 &, 040 &, 000 & .000 & .530 & & .000 &, 085 &, 000 \\
\hline & $N$ & 92 & 92 & 92 & 92 & 92 & 92 & 92 & 92 & 92 \\
\hline \multirow[t]{3}{*}{ PER7 } & Pearson Correlation &,- 031 & $.215^{x}$ & $.976^{x x}$ & $1,000^{x x}$ &,- 066 & $1,000^{x x}$ & 1 & .180 & $.808^{x x}$ \\
\hline & Sig. (2-tailed) & .766 &, 040 & .000 & .000 & .530 &, 000 & & .085 &, 000 \\
\hline & $N$ & 92 & 92 & 92 & 92 & 92 & 92 & 92 & 92 & 92 \\
\hline \multirow[t]{3}{*}{ PER8 } & Pearson Correlation & $275^{x x}$ & $.364^{2 x}$ & .156 & .180 & .200 & .180 & .180 & 1 & $.524^{2 \pi x}$ \\
\hline & Sig. (2-tailed) &, 008 &, 000 & .136 & .085 &, 056 & .085 & .085 & &, 000 \\
\hline & $N$ & 92 & 92 & 92 & 92 & 92 & 92 & 92 & 92 & 92 \\
\hline \multirow[t]{3}{*}{ T_SKOR } & Pearson Correlation & $.421^{\pi x}$ & $.558^{x x}$ & $.786^{2 x}$ & $808^{x x}$ & $.356^{x x}$ & $.808^{x x}$ & $.808^{x \times x}$ & $.524^{x \times x}$ & 1 \\
\hline & Sig. (2-tailed) & .000 &, 000 &, 000 & .000 &, 000 &, 000 &, 000 &, 000 & \\
\hline & $N$ & 92 & 92 & 92 & 92 & 92 & 92 & 92 & 92 & 92 \\
\hline
\end{tabular}

${ }^{*}$. Correlation is significant at the 0.05 level (2-tailed).

$\rightarrow$ Correlation is significant at the 0.01 level (2-tailed)

Bila kita lihat $\mathrm{r}$ hitung pada $\mathrm{T} \_s k o r$ semua pernyataan 1 sampai dengan pernyataan 8 hasilnya diatas $\mathrm{r}$ tabel $=0,1726$ maka dapat kita katakan Data $\mathrm{X}$ semua pernyataannya valid.

Untuk validitas data Y (minat menjadi entrepreneur) di dapat hasil dari pengolahan data dengan menggunkan SPSS 19 sebagai berikut:

Validitas Data Y (minat menjadi entrepreneur) 


\section{Correlations}

\begin{tabular}{|c|c|c|c|c|c|c|}
\hline & & PER1 & PER2 & PER3 & PER4 & T_SKOR \\
\hline \multirow[t]{3}{*}{ PER1 } & & 1 &,- 066 &,- 066 & 200 & $426^{\mathrm{xx}}$ \\
\hline & Sig. (2-tailed) & &, 530 &, 530 &, 056 &, 000 \\
\hline & $\mathbb{N}$ & 92 & 92 & 92 & 92 & 92 \\
\hline \multirow[t]{3}{*}{ PER2 } & Pearson Correlation &,- 066 & 1 & $1,000^{\pi x}$ & .180 & $.782^{\pi x}$ \\
\hline & Sig. (2-tailed) & .530 & & 000 & ,085 & 000 \\
\hline & $N$ & 92 & 92 & 92 & 92 & 92 \\
\hline \multirow[t]{3}{*}{ PER3 } & Pearson Correlation &,- 066 & $1,000^{x \pi}$ & 1 & , 180 & $.782^{x \pi}$ \\
\hline & Sig. (2-tailed) & .530 & 000 & & ,085 &, 000 \\
\hline & $N$ & 92 & 92 & 92 & 92 & 92 \\
\hline \multirow[t]{3}{*}{ PER4 } & Pearson Correlation & .200 &, 180 & .180 & 1 & $.625^{x \pi}$ \\
\hline & Sig. (2-tailed) &, 056 &, 085 & ,085 & &, 000 \\
\hline & $N$ & 92 & 92 & 92 & 92 & 92 \\
\hline \multirow[t]{3}{*}{$T_{-S K O R}$} & Pearson Correlation & $426^{x \pi}$ & $.782^{x x}$ & $.782^{x x}$ & $625^{x \pi}$ & 1 \\
\hline & Sig. (2-tailed) &, 000 &, 000 &, 000 &, 000 & \\
\hline & N & 92 & 92 & 92 & 92 & 92 \\
\hline
\end{tabular}

*. Correlation is significant at the 0.01 level (2-tailed).

Bila kita lihat $\mathrm{r}$ hitung pada $\mathrm{T} \_$skor semua pernyataan 1 sampai dengan pernyataan 4 hasilnya diatas $\mathrm{r}$ tabel $=0,1726$ maka dapat kita katakan Data $\mathrm{Y}$ semua pernyataannya valid.

\section{Reliabilitas}

Alat ukur yang digunakan dalam penelitian ini adalah kuesioner, untuk itu ketepatan alat ukur yang akan digunakan dalam wawancara sangatlah penting. Menurut Sugiyono (2014), bahwa reliabilitas instrumen adalah ketepatan alat ukur yang digunakan beberapa kali dalam mengukur objek yang sama maka akan menghasilkan data yang sama. Dan dari hasil uji reliabilitas data $\mathrm{X}$ (tingkat pengetahuan kewirausahaan) didapatkan hasil sebagai berikut : 


\begin{tabular}{|c|c|c|c|}
\hline & & $\mathrm{N}$ & $\%$ \\
\hline \multirow[t]{3}{*}{ Cases } & Valid & 92 & 100,0 \\
\hline & Excluded $^{a}$ & 0 & , 0 \\
\hline & Total & 92 & 100,0 \\
\hline
\end{tabular}

a. Listwise deletion based on all variables in the procedure.

Reliability Statistics

\begin{tabular}{|r|r|}
\hline $\begin{array}{l}\text { Cronbach's } \\
\text { Alpha }\end{array}$ & N of Items \\
\hline, 771 & 8 \\
\hline
\end{tabular}

Item-Total Statistics

\begin{tabular}{|c|c|c|c|c|}
\hline & $\begin{array}{l}\text { Scale Mean if } \\
\text { Item Deleted }\end{array}$ & $\begin{array}{l}\text { Scale Variance } \\
\text { if Item Deleted }\end{array}$ & $\begin{array}{c}\text { Corrected Item- } \\
\text { Total } \\
\text { Correlation }\end{array}$ & $\begin{array}{c}\text { Cronbach's } \\
\text { Alpha if Item } \\
\text { Deleted }\end{array}$ \\
\hline PER1 & 32,52 & 5,483 & ,199 & ,800 \\
\hline PER2 & 32,43 & 5,194 & ,388 & ,761 \\
\hline PER3 & 32,40 & 4,749 & ,696 & ,710 \\
\hline PER4 & 32,41 & 4,685 & ,724 & ,704 \\
\hline PER5 & 32,45 & 5,744 & ,164 & ,796 \\
\hline PER6 & 32,41 & 4,685 & ,724 & ,704 \\
\hline PER7 & 32,41 & 4,685 & ,724 & ,704 \\
\hline PER8 & 32,49 & 5,264 & ,344 & ,769 \\
\hline
\end{tabular}

Hasil uji reliabilitas data X dengan SPPS 19 didapat Cronbach's alpha sebesar 0,771 artinya lebih besar dari $r$ tabel sebesar 0,1726, dapat kita simpulkan data $X$ adalah reliabel/ konsisten.

Dan hasil uji reliabilitas data Y (minat menjadi entrepreneur) dengan menggunakan SPPS19, didapatkan hasil sebagai berikut : 
Reliability Statistics

\begin{tabular}{|r|r|}
\hline \multicolumn{1}{|c|}{$\begin{array}{l}\text { Cronbach's } \\
\text { Alpha }\end{array}$} & N of Items \\
\hline, 541 & 4 \\
\hline
\end{tabular}

\begin{tabular}{|c|c|c|c|}
\hline \multicolumn{4}{|c|}{ Case Processing Summary } \\
\hline & & $\mathrm{N}$ & $\%$ \\
\hline \multirow[t]{3}{*}{ Cases } & Valid & 92 & 100,0 \\
\hline & Excluded $^{a}$ & 0 & ,0 \\
\hline & Total & 92 & 100,0 \\
\hline
\end{tabular}

a. Listwise deletion based on all variables in the procedure.

\begin{tabular}{|l|r|r|r|r|}
\hline & & Item-Total Statistics & \\
& Scale Mean if & Scale Variance & $\begin{array}{c}\text { Corrected Item- } \\
\text { Total } \\
\text { Item Deleted }\end{array}$ & $\begin{array}{c}\text { Cronbach's } \\
\text { Alpha if Item } \\
\text { if Item Deleted }\end{array}$ \\
& 13,91 & 1,377 &, 038 &, 693 \\
PER1 & 13,88 &, 942 &, 555 &, 269 \\
PER2 & 13,88 &, 942 &, 555 &, 269 \\
PER3 & 13,96 & 1,097 &, 260 &, 530 \\
PER4 & & & & \\
\hline
\end{tabular}

Hasil uji reliabilitas data Y dengan SPPS 19 didapat Cronbach's alpha sebesar 0,541 artinya lebih besar dari $r$ tabel sebesar 0,1726, dapat kita simpulkan data $Y$ adalah reliabel/ konsisten.

\section{Regresi}

Uji regresi sederhana antara variabel independen $\mathrm{X}$ terhadap variabel dependen Y didapat hasil pengujian sebagai berikut: 


\begin{tabular}{|c|c|c|c|}
\hline \multicolumn{4}{|c|}{ Variables Entered/Removed $^{\mathrm{b}}$} \\
\hline Model & $\begin{array}{c}\text { Variables } \\
\text { Entered }\end{array}$ & $\begin{array}{l}\text { Variables } \\
\text { Removed }\end{array}$ & Method \\
\hline 1 & Data $X^{a}$ & & Enter \\
\hline
\end{tabular}

a. All requested variables entered.

b. Dependent Variable: Data_Y

Dari tabel di atas dapat dijelaskan bahwa variabel yang dimasukan atau dibuang adalah variabel nilai trust (data $\mathrm{X}$ ) sebagai predictor dan metode yang digunakan adalah metode enter.

Model Summary

\begin{tabular}{|l|r|r|r|r|}
\hline Model & R & R Square & \multicolumn{1}{|c|}{$\begin{array}{l}\text { Adjusted R } \\
\text { Square }\end{array}$} & $\begin{array}{l}\text { Std. Error of the } \\
\text { Estimate }\end{array}$ \\
\hline 1 &, $949^{a}$ &, 901 &, 900 &, 410 \\
\hline
\end{tabular}

a. Predictors: (Constant), Data_X

Dari tabel di atas dapat dijelaskan bahwa besarnya nilai koefisien korelasi/ hubungan $(R)$ adalah 0,949, serta koefisien determiniasi $\left(\mathbf{R}^{2}\right)$ bermakna bahwa pengaruh variabel bebas $X$ (tingkat pengetahuan kewirausahaan) terhadap variabel Y (minat menjadi entrepreneur) terikat sebesar $\mathbf{R}^{\mathbf{2}}=\mathbf{0 , 9 0 1}$. Dapat dikatakan pula pengaruh variabel Trust (bebas) terhadap variabel terikat sebesar 90,1\%. Menurut Sarwono (2006) bahwa nilai koefisien korelasi (R) memiliki tingkatan yaitu :

$\mathrm{R}=0$ artinya antara variabel $\mathrm{X}$ dan $\mathrm{Y}$ tidak mepunyai korelasi (hubungan)

$$
\begin{aligned}
& 0,00 \text { sd 0,25 korelasi variabel } X \text { dan } Y \text { sangat lemah } \\
& 0,25 \text { sd 0,50 korelasi variabel } X \text { dan } Y \text { cukup } \\
& 0,50 \text { sd 0,75 korelasi variabel } X \text { dan } Y \text { kuat } \\
& 0,75 \text { sd 0,99 korelasi variabel } X \text { dan } Y \text { sangat kuat }
\end{aligned}
$$

Sehingga dapat disimpulkan bahwa tingkat pengetahuan kewirausahaan 90,1\% sangat kuat mempengaruhi minat mahasiswa menjadi entrepreneur, sisanya 9,9\% 
dipengaruhi oleh faktor lain seperti permodalan, merasa belum berpengalaman, takut mengalami kerugian, terlalu banyak berpikir, akses pasar, dan lain sebagainya.

\begin{tabular}{|c|c|c|c|c|c|c|}
\hline \multicolumn{7}{|c|}{ ANOVA $^{b}$} \\
\hline & & Sum of Squares & $d f$ & Mean Square & $\mathrm{F}$ & Sig. \\
\hline \multirow[t]{3}{*}{1} & Regression & 137,690 & 1 & 137,690 & 818,696 &, $000^{a}$ \\
\hline & Residual & 15,136 & 90 & , 168 & & \\
\hline & Total & 152,826 & 91 & & & \\
\hline
\end{tabular}
a. Predictors: (Constant), Data_X
b. Dependent Variable: Data_Y

Dari tabel Anova diatas bisa kita lihat nilai F hitung sebesar 818,696 dengan tingkat signifikansi atau probabilitas $0,000<0,005$ maka model regresi dapat dipakai untuk memprediksi variabel partisipasi (Y).

\begin{tabular}{|c|c|c|c|c|c|c|}
\hline \multicolumn{7}{|c|}{ Coefficients $^{a}$} \\
\hline \multirow{2}{*}{\multicolumn{2}{|c|}{ Model }} & \multicolumn{2}{|c|}{ Unstandardized Coefficients } & \multirow{2}{*}{$\begin{array}{c}\text { Standardized } \\
\text { Coefficients } \\
\text { Beta }\end{array}$} & \multirow[b]{2}{*}{$\mathrm{t}$} & \multirow[b]{2}{*}{ Sig. } \\
\hline & & $\mathrm{B}$ & Std. Error & & & \\
\hline \multirow[t]{2}{*}{1} & (Constant) &, 517 & ,631 & & 819 & ,415 \\
\hline & Data_X & ,486 &, 017 & ,949 & 28,613 &, 000 \\
\hline
\end{tabular}

a. Dependent Variable: Data_Y

Dari tabel di atas didapat hasil nilai Constanta (a) sebesar 0,517 dan nilai Trust (Data_X) sebesar 0,486. Dengan demikian dapat disusun persamaan regresi sederhana $\mathrm{Y}=\mathrm{a}+\mathrm{bX}$ menjadi :

$$
Y=0,517+0,486 X
$$

Dan hasil uji t yang merupakan uji terhadap hipotesis nol $(\mathrm{H} 0)$, didapat nilai uji $\mathrm{t}=$ 28,613 sementara nilai $\mathrm{t}$ tabel $\mathrm{df}=\mathrm{N}-2$, dengan signifikansi 0,05 , didapat nilai $\mathrm{t}$ tabel $=1.98667$ berarti nilai $\mathrm{t}$ hitung $>\mathrm{t}$ tabel, maka hipotesa $\mathrm{H} 0$ ditolak dan 
hipotesa $\mathrm{H} 1$ diterima, artinya Ada pengaruh tingkat pengetahuan kewirausahaan terhadap minat menjadi entrepreneur pada mahasiswa.

\section{SIMPULAN}

Bahwa modal utama untuk menjadi entrepreneur adalah tingkat pengetahuan kewirausahaan yang kuat meliputi pengetahuan mengenai usaha yang akan dirintis, tekad/ tanggung jawab, yakin akan kemampuan diri dan pengetahuan organisasi bisnis. Akan tetapi ada juga hambatan untuk menjadi etrepreneur seperti tidak memiliki modal, takut mengalami kerugian, merasa kurang berpengalaman, dan masih terlalu banyak berpikir.

Dan kampus UBSI telah memberikan bekal pengetahuan entrepreneurship melalui matakuliah enterpreneur, seminar seminar, workshop maupun pameran yang telah menjadi program kampus UBSI yang diadakan oleh lembaga BSI Entrepreneur Center http://bec.bsi.ac.id. Sehingga dapat dikatakan sangat kuat pengaruh pengetahuan kewirausahaan yang diberikan lembaga BSI Entrepreneur kepada mahasiswa UBSI kampus salemba 22 Jakarta untuk menumbuhkan minat menjadi Entrepreneur.

\section{DAFTAR RUJUKAN}

Arikunto, S.(2006). Metode Penelitian Kuantitatif. Jakarta: Bumi Aksara.

Ebert, R. J \& Griffin, R. W. (2006). Bussiness (terjemahan: Sitha Wardhani). Jakarta: Penerbit Erlagga.

Hartaji, Damar A.(2012).Motivasi Berprestasi Pada Mahasiswa yang Berkuliah Dengan Jurusan Pilihan Orang Tua. Skripsi Strata Satu, Fakultas Psikologi Universitas Gunadarma.

Jonathan, Sarwono.(2006).Metode Penelitian Kuantitatif dan Kualitatif. Yogyakarta: Graha Ilmu.

Kuntowicaksono, (2012).Pengaruh Pengetahuan Wirausaha dan Kemampuan Memecahkan Masalah Kewirausahaan Terhadap Minat Berwirausaha Siswa Sekolah Menengah Kejuruan: Journal of Economic Education.

Slameto.(2003).Belajar dan Faktor-Faktor yang Mempengaruhinya. Jakarta: Rineka Cipta.

Sugiyono.(2014).Metode Penelitian Pendidikan Pendekatan Kuantitatif, Kualitatif Dan $R \& D$. Bandung: Alfabeta. 
Suryana.(2014), Kewirausahaan, Edisi .IV Jakarta: Salemba 4.

Winkel, W. S.(2004).Psikologi Pendidikan dan Evaluasi Belajar. Jakarta: PT. Gramedia Pustaka Utama.

Yusuf, Syamsu.(2012).Psikologi Perkembangan Anak dan Remaja. Bandung: Remaja Rosdakarya.

Zimmerer, Thomas W dan Norman Scarborough,(2008). Kewirausahaan dan Manajemen Usaha Kecil. Jakarta: Salemba4.

https://www.cnnindonesia.com/ekonomi/20191105154437-532-445788/angkapengangguran-naik-jadi-705-juta-orang-per-agustus-2019

https://katadata.co.id/infografik/2019/05/17/angka-pengangguran-lulusanperguruan-tinggi-meningkat\#

https://nasional.kompas.com/read/2019/04/23/15285921/jokowi-kemudahaninvestasi-membaik-indonesia-jadi-incaran-investor-asing https://www.dosenpendidikan.co.id/entrepreneur-adalah/ https://www.shutterstock.com/search/entrepreneur+building?image type=vector\& $\underline{\text { search_source }=\text { base_related_searches }}$ 